\title{
Sobre o Futuro dos Médicos-Cientistas Portugueses
}

\section{On the Future of Portuguese Physician-Scientists}

\author{
Célia Azevedo SOARES $\triangle^{1 *}$, João INCIO ${ }^{2,3}$, Miguel Reis FERREIRA4, João BARBOSA-BREDA ${ }^{5,6,7}$, Liliana PÁRIS ${ }^{8,9}$, \\ José Luís SANDOVAL $\triangle^{10,11 *}$ \\ Acta Med Port 2016 Dec;29(12):793-795 - http://dx.doi.org/10.20344/amp.8388
}

Palavras-chave: Educação Médica; Investigação Biomédica; Médicos; Portugal.

Keywords: Biomedical Research; Education, Medical; Physicians; Portugal.

Desde os primórdios da medicina que a produção de conhecimento científico é parte integrante das funções que um médico pode desempenhar, em paralelo com a atividade assistencial, promoção da saúde e ensino. Algumas academias estrangeiras valorizam de tal forma as valências em investigação que as incluem na sua lista de competências para a prática da medicina moderna orientada para as necessidades do doente. ${ }^{1}$

A redução da mortalidade e morbilidade de várias patologias deve-se em grande parte ao trabalho científico de médicos como Virchow, Osler, Cushing, Snow, Doll ou dos portugueses Egas Moniz e Corino de Andrade.

Contudo, cada salto quântico nas ciências médicas está baseado na permanente acumulação de conhecimento fruto do trabalho de muitos médicos-cientistas, longe dos holofotes dos prémios Pfizer, Lasker ou Nobel. Tal como a prática médica evolui para uma maior complexidade com a necessidade de formações específicas, a investigação médica também exige conhecimentos e competências cada vez mais específicos, com necessidades formativas próprias. Nas últimas décadas assistiu-se em Portugal a um forte investimento na área da formação médica em investigação, muitas vezes através de formações pós-graduadas com ou sem atribuição de grau académico. Este investimento produziu médicos-cientistas em diferentes graus de desenvolvimento e cujo contributo pretende melhorar a quantidade e a qualidade da investigação médica em Portugal. Não obstante, várias são as barreiras a ultrapassar de modo a explorar todo o potencial da atual e futuras gerações de médicos-cientistas.

Neste artigo, que marca a primeira intervenção pública de um recém-criado grupo de médicos-cientistas portugue- ses, pretende-se discutir os problemas mais comuns que enfrentam os médicos-cientistas e que funcionam como forças de atrito no desenvolvimento da sua atividade.

Um bom exemplo de formação de médicos-cientistas é o programa Harvard Medical School Portugal. Ao longo dos últimos seis anos proporcionou formação científica a mais de 160 médicos, através de formação em Portugal com docentes de Harvard e financiando períodos de formação na universidade americana. Outro exemplo é o Programa de Formação Médica Avançada (PFMA) patrocinado pela Fundação Calouste Gulbenkian, Fundação Champalimaud e Ministério da Saúde o qual aceitou candidatos pela última vez em 2011.

Em 2015/2016 realizou-se um inquérito informal aos alunos do PFMA para conhecer as suas perspetivas após finalizarem o Programa. De um grupo de 38 alunos, 24 responderam ao inquérito. Apesar de $95 \%$ planear fazer investigação pós-doutoral em Portugal a dada altura da carreira, apenas $30 \%$ pretende realizá-la no imediato. Quando questionados sobre o que os atrai fora de Portugal, as opções com mais votos foram a disponibilidade de financiamento apropriado para investigação clínica e a existência de uma massa crítica. Quando questionados sobre as maiores dificuldades que anteviam na realização de investigação em Portugal, a opção mais votada, com $87 \%$ dos votos, foi a inexistência de uma carreira de médico-investigador e a impossibilidade de se profissionalizarem como tal. Seguidamente, encontravam-se a falta de tempo para combinar as atividades assistencial e de investigação, a expectativa de não conseguir bolsas para investigação e a falta de massa crítica.

De modo a obter a opinião de uma base mais alargada

\footnotetext{
* Co-primeiros autores

1. Hospital de Braga. Braga. Portugal.

2. Serviço de Medicina Interna. Centro Hospitalar São João. Porto. Portugal.

3. I3S - Instituto de Investigação e Inovação em Saúde. Universidade do Porto. Porto. Portugal.

4. Institute of Cancer Research. The Royal Marsden Hospital. Londres. Reino Unido.

5. Departamento de Oftalmologia. Centro Hospitalar São João. Porto. Portugal.

6. Faculdade de Medicina. Universidade do Porto. Porto. Portugal.

7. Department of Biomedical Sciences. Katholieke Universiteit Leuven. Lovaina. Bélgica.

8. Instituto de Oftalmologia Dr. Gama Pinto. Lisboa. Portugal.

9. Department of Cell and Molecular Biology. The Friedlander Laboratory. The Scripps Research Institute. La Jolla. Estados Unidos da América.

10. Unidade de Epidemiologia Populacional. Hospitais Universitários de Genebra. Genebra. Suíça.

11. Departamento de Medicina Interna. Hospitais Universitários de Genebra. Genebra. Suíça.

$\square$ Autores correspondentes: Célia Azevedo Soares. cmas00@gmail.com; José Luís Sandoval. jose.sandoval@cantab.net

Recebido: 10 de outubro de 2016 - Aceite: 23 de novembro de 2016 | Copyright @ Ordem dos Médicos 2016
} 
e perceber se é similar à dos alunos do PFMA, recorremos às redes sociais e convidámos um grupo de médicos-cientistas a identificar os problemas que enfrentam regularmente e cuja resolução é premente. ${ }^{2}$ Os mais destacados, podendo os participantes escolher mais do que uma hipótese, foram: 1) necessidade de tempo protegido para atividades de investigação $(18 / 21,85,7 \%)$ e 2$)$ falta de financiamento específico (16/21, 76,2\%) (Fig. 1).

Importa referir que os dados mencionados neste artigo são escassos e provenientes de questionários não validados, impossibilitando uma correta avaliação do panorama nacional dos médicos-cientistas. Atividades futuras da responsabilidade da nova associação irão permitir uma melhor caracterização desta população.

Apesar das limitações mencionadas, estes inquéritos mostraram de maneira reprodutível um foco em dois temas - existência de tempo dedicado para investigação e financiamento.

A prioridade dada a estes problemas não é um exclusivo da realidade portuguesa. No último encontro da European MD/PhD Association foi apresentado um estudo realizado em três países no qual estas duas questões lideravam a lista de preocupações dos médicos-cientistas europeus (resultados não publicados), realçando a necessidade de otimizar a carreira de médico-cientista não apenas em Portugal, mas também no espaço europeu.

$\mathrm{Na}$ maioria das instituições de saúde portuguesas, os médicos-cientistas 'praticantes' são a exceção e não a regra. As suas necessidades em termos de tempo para planear, executar e reportar estudos científicos não estão devidamente acauteladas. A ausência de tempo protegido faz com que a ciência produzida seja resultado de um enorme esforço, sem uma organização temporal estruturada.
Ainda que se perceba que o tempo protegido não possa ser uma condição pré-existente para a realização de toda a atividade científica, é importante que, quando atingido um certo grau de maturidade de investigação, os médicos que assim o desejem possam planear uma carreira na qual a investigação tenha um peso substancial, com prejuízo das atividades assistenciais ou letivas. Existem atualmente em instituições portuguesas casos de médicos com contratos que contemplam tempo protegido para investigação. No entanto, são oportunidades raras e oferecidas localmente, não harmonizadas a nível central.

O financiamento em investigação é fundamental, contribuindo para a aquisição de materiais e equipamento, contratação de elementos para a criação de uma equipa de investigação, financiamento de deslocações para comunicação de resultados e até para o pagamento dos custos de publicação em revistas. O impacto dum projeto de investigação depende também dos fundos disponíveis para o seu financiamento. Torna-se então importante que os médicos-cientistas em Portugal tenham financiamento próprio para a realização dos seus projetos. Muito do financiamento da investigação clínica portuguesa (sem ligação à indústria farmacêutica) baseia-se principalmente em prémios atribuídos após a conclusão de um projeto científico. Apesar do mérito destas iniciativas, não suprem as necessidades de financiamento de projetos individuais numa fase de planeamento, tal como acontece nas ciências básicas. Um aumento de bolsas de investigação clínica numa fase precoce poderia incentivar a realização de mais projetos desta índole e rentabilizar o investimento que tem sido feito na formação de profissionais de saúde em investigação.

A Resolução do Conselho de Ministros n. ${ }^{\circ}$ 18/2015 propôs importantes passos para a estruturação de uma

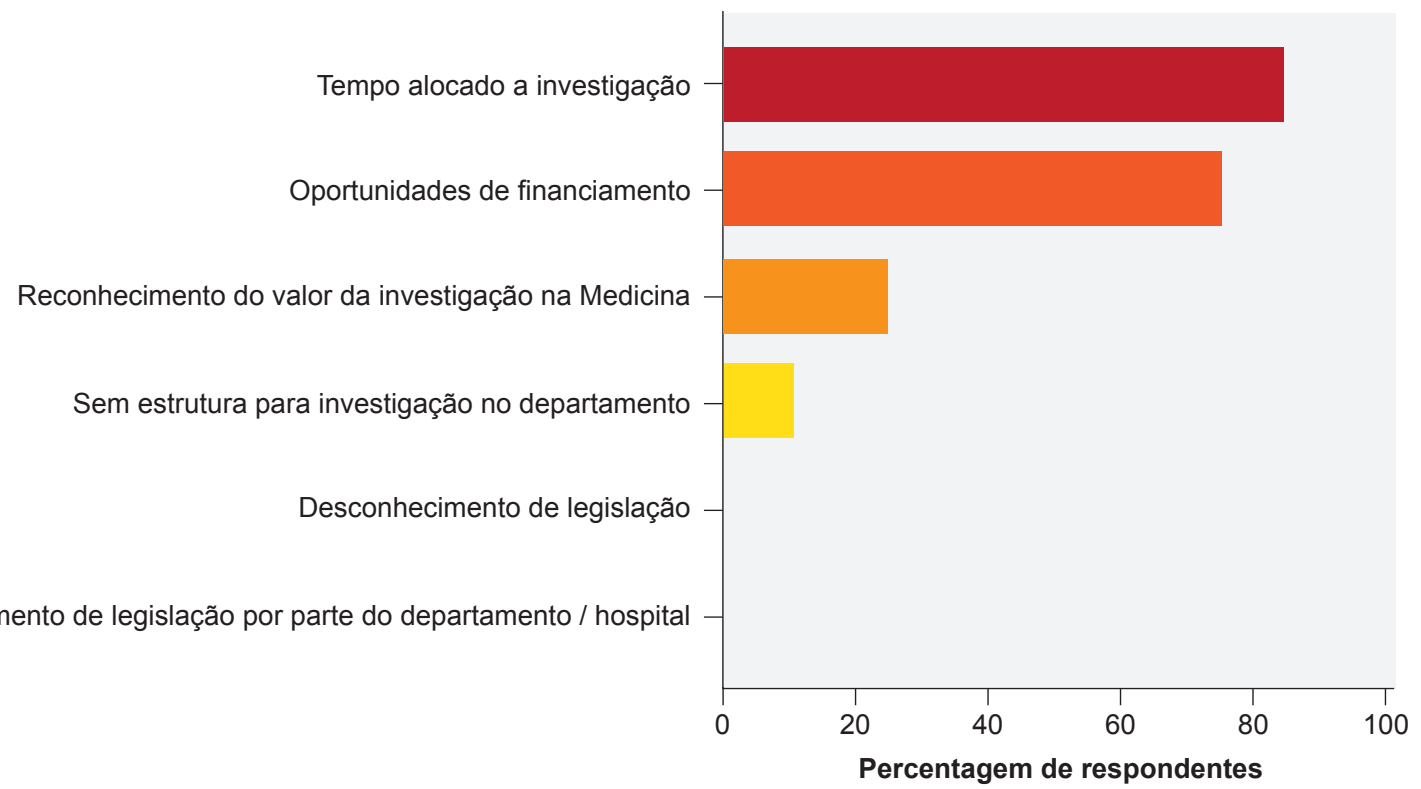

Figura 1 - Inquérito sobre as dificuldades após formação medica pós-graduada. Na página 'Médicos-Cientistas Portugueses' na rede social Facebook, foi colocada a questão "Quais as maiores dificuldades que médicos com formação pós-graduada encontram no atual Sistema de Saúde?". Das respostas possíveis, as respostas com mais votos foram "Tempo alocado a investigação", "Oportunidade de financiamento" e "Reconhecimento do valor da investigação na Medicina". 
carreira de médico-cientista em Portugal, ${ }^{3}$ sugerindo soluções para as duas problemáticas identificadas pelos médicos-cientistas que consultámos. Para a questão do tempo dedicado seria criado o Programa do Investigador Médico para médicos especialistas com doutoramento e com seleção por candidaturas competitivas. Este programa permitiria que o médico investigador dedicasse pelo menos $75 \%$ do seu tempo hospitalar à investigação, e incluiria o pagamento do salário do médico assim como uma verba para financiamento da atividade de investigação, durante um período de cinco anos.

Outro ponto que esta resolução destaca é a necessidade de "distinguir os projetos de investigação clínica que

\section{REFERÊNCIAS}

1. Royalcollege.ca. Ottawa: The Royal College of Physicians and Surgeons of Canada; [consultado 2016 out 30]. Disponivel em: http://www. royalcollege.ca/rcsite/canmeds/framework/canmeds-role-scholar-e.

2. Facebook.com/groups/medicoscientistaspt/. Médicos Cientistas Portugueses. [consultado 2016 out 23]. Disponível em: https://www.facebook. tradicionalmente têm sido avaliados conjuntamente com os projetos de investigação fundamental, criando painéis de avaliação específicos", listando várias opções como, por exemplo, o financiamento de cinco projetos em investigação clínica por ano com o montante de 250 mil euros por projeto.

Apesar de publicada, o calendário para a aplicação desta resolução continua por definir.

Enquanto o aprimorar de soluções políticas decorre, cabe a nós, médicos portugueses, novos ou mais velhos, cientistas ou não, procurar que a nossa Medicina caminhe para o futuro, apoiando o trabalho dos médicos-cientistas. O futuro da Medicina portuguesa depende de tal.

com/groups/medicoscientistaspt/permalink/1254803077887438/.

3. Resolução n. ${ }^{\circ}$ 18/2015 de 19 de Março de 2015 do Conselho de Ministros. Diário da República: I série, No 67. [Consultado 2016 set 10] Disponível em: https://dre.pt/application/file/66934077. 